\title{
Climate and Water
}

\author{
Oleg Halidullin* \\ Ecology Professor, Russiac \\ *Corresponding author: Oleg Halidullin, Ecology Professor, Russia
}

Submission: 眥January 11, 2019; Published: 輩 January 24, 2019

Keywords: Climate change; Artificial evaporation; Organic evaporation; Quality of evaporation; Evaporation rate; Evaporation volumes; Short-circuited circuit; Underground cities; Roofs planting

\section{Introduction}

As a result of human activity, the natural functions of fresh water are changing. Instead of containing biota -a community of living organisms and plants -and undergoing a full cycle of transformations in food paths, water comes with precipitation and returns to the atmosphere by artificial evaporation from arable land, asphalt, reservoirs, landfills. Humanity produces even more distorted vapors when washing, drying, in the industry, turning water into a working reagent. The destruction of the water cycle is the root of climate change. In total, humans have taken away from nature $63 \%$ of the inhabited land according to 2015. Biota consumes water, transforms it in its bodies and releases, exhales a special structure of moisture, purely individual fumes, which we call natural or organic fumes. Human intervention in the circulation of water reduces the ways of its transformation, and water from the destroyed territories and technological processes evaporates without fulfilling the natural purposes. Total artificial evaporation creates new amounts of water, with new accelerated cycles, a new substance in the atmosphere, which destroys the mechanism of atmospheric phenomena that has been established for millions of years. The cyclicity, massiveness and precipitation zones have changed. Rising oceans can be explained by the fact that new weighted clouds do not reach the polar and mountain glaciers and do not replenish their volumes, spilling along the road. Fighting carbon dioxide emissions, master ing "green" technologies are useful, but microscopic movements. We must pay attention to the evaporation. Only artificial evaporation in the atmosphere of 22 trillion tons, even more, while preserved, organic. A total carbon dioxide- 4 billion tons. Research is needed and to prove the reality of the hypothesis. Calculate the true volumes of these evaporations, measure the geography of precipitation, considering their volumes. And based on this, create a new concept of climate conservation. This is the only way to save life on the planet.

Among the measures to reduce artificial evaporation should be the total saving of water in everyday life by every person, every enterprise of all branches of agriculture and industry. This will require the reconstruction of all agriculture with the introduction of shallow plowing, drip irrigation, revision of all work related to the change and accumulation of water in rivers, the elimination of all landfills and lakes-reservoirs. In industry and municipal processes, urgently master the repeated use of water and reduce its consumption. Revise the urban infrastructure with a gradual release of space for plants, the transfer of plants and everything else, including housing, underground. Of course, not immediately. The walls and roofs of existing buildings and structures covered with greenery. To do this, master a new branch of the crop-to get fruits and vegetables on the walls and roofs.
Creative Commons Attribution 4.0 International License

For possible submissions Click Here
Submit Article

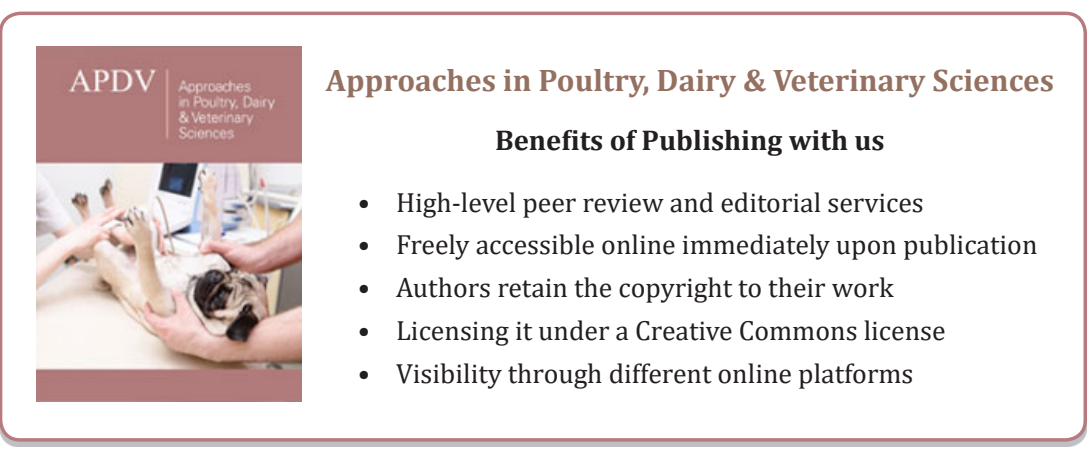

